\title{
Body Proximity in PSE Sessions, in Arab-Muslim Countries: Case of Tunisia
}

\author{
Ben Chaifa Mounira', Abdelmajid Naceur ${ }^{2}$, Elloumi Mohamed ${ }^{3}$ \\ ${ }^{1}$ ISEFC Tunis RU: ECOTIDI, Tunis, Tunisia \\ ${ }^{2}$ ISEFCRU: ECOTIDI, Tunis, Tunisia \\ ${ }^{3}$ ISSEP Tunis MCO-HD2, Tunis, Tunisia \\ Email: mounirabenchaifa@gmail.com
}

How to cite this paper: Mounira, B. C., Naceur, A., \& Mohamed, E. (2018). Body Proximity in PSE Sessions, in Arab-Muslim Countries: Case of Tunisia. Advances in Physical Education, 8, 84-97. https://doi.org/10.4236/ape.2018.81010

Received: December 3, 2017

Accepted: February 10, 2018

Published: February 13, 2018

Copyright (c) 2018 by authors and Scientific Research Publishing Inc. This work is licensed under the Creative Commons Attribution International License (CC BY 4.0).

http://creativecommons.org/licenses/by/4.0/

(c) (i) Open Access

\begin{abstract}
Physical education and sport (PSE), discipline of education, is based on the use of the physical motority. This particularity will confront the actors to emotionally charged situations. For our study, we look for the impact of gender and seniority of PSE teacher on the interpersonal distances observed during the PSE sessions. We have collaborated with 20 PSE teachers and 10 student trainees undergoing initial training in secondary schools. We made video recordings of PSE sessions, and 2 interviews with each registered teacher. Our results show that intervention strategies during the practical sessions are marked by regularity and typicality of use on the part of EPS teachers, the use of the same proxemic categorizations in the teaching practices. The teachers approach the student for the individual correction and they move away to observe the whole class. However, teachers remain vigilant for the safety of pupils and especially for girls.
\end{abstract}

\section{Keywords}

Proxemic Categorization, Didactic Distance, Professional Seniority, Gender, PSE

\section{Introduction}

In physical education and sports, the classes are mixed: boys and girls follow the same teaching content and get together to practice various physical and sports activities. Moreover, the context and the object of the teaching of the physical education and sport (PSE) are particular, on the one hand, the places of teaching are multiple (ground, room, swimming pool...) and on the other hand, the contents taught are also part of a particular context, related on the one hand to the 
various fields of knowledge (psychology, sociology, physiology...) and on the other hand, they are part of the social practices of reference (Martinand, 1981), this learning support puts, the body of the teacher, as well as that of the pupil at play. This particularity, in EPS, to use the body motricity will confront these actors to emotionally charged situations. The physical education and sports teacher uses his body to communicate some information (Boizumault \& Cogérino, 2010, 2012), during his interactions with his pupils. He uses verbal communication and nonverbal communication to ensure student learning. According to Genevois (1992), it is within verbal and nonverbal elements that learning is constructed.

\section{Proxemic Categorization}

The author (Burel, 2014) asserts that other than the mission of the teacher of EPS to improve the motricity of the student who is played directly on the body by the physical contact is added the evolution of the pupils according to complex spatio-temporal configurations favoring more proximity. For Boizumault \& Cogérino (2012) the teacher's body is often used during his didactic pedagogical interventions at various distances. We owe the American (Hall, 1963, 1968, 1971), the first research work on proxemics. This anthropologist has observed that animals keep certain constant distances between them, and men, too, maintain identical and uniform distances in their relations with each other. These observations allowed the author to define four types of distance that men maintain during their interactions: intimate, personal, social and public, these distances are divided into two modes: close mode and remote mode. The proxemic would be defined as “all observations and theories concerning man's use of space as a cultural product" (Hall, 1971). It should also be noted that this typology of distance Hall was then used in this work to analyze the behavior of individuals from different cultures.

The proxemic typology of Hall also served as an exploratory model in the work of (Forest, 2001) for class situation analysis. The Hall model has proved its fertility in this study, which researchers have encouraged (Forest, 2006a, 2006b, 2008; Sensevy, Forest, \& Barbu, 2005), to adapt it to study didactic interactions. These authors were able to identify proxemic categorizations of the mathematics teacher. For Sensevy et al. (2005) their proxemic categorizations seem to be more adequate to the reality of the class than that elaborated by Hall (1963). The teacher can, regularly change configuration or keep it. He can, also, following a problem of disciplinary order, for a given configuration, to cause an increase of the distances. Sensevy et al. (2005) argue that Euclidean (geometric) distance alone cannot account for distances perceived by the teacher and the learners from which other determinants come into play. These authors conclude that One must take into consideration, other than the Euclidean distance, the orientation of the body and that of the gaze. The distance is postulated by these authors "the didactic distance" which will be "a function of the Euclidean distance, 
the orientation of the body and that of the gaze" (Sensevy et al., 2005: p. 666; Forest, 2006: p. 78).

In light of these data, our study is interested in answering the following questions: Are the conceptions of interpersonal distance learning PSE teachers in practical sessions influenced by the teacher's gender and/or professional seniority? Do the gender and/or professional seniority of the PSE teacher act on the physical distance between him and his pupils during the practical sessions? Are proxemic categorizations the same for all PSE teachers?

\section{Methodology}

To answer these questions, we collaborated with 20 PSE teachers, including 10 experienced and 10 beginners, and 10 trainee students in initial training at secondary schools. They are divided into 15 men and 15 women. The participants belong to the same region which is devised in four governorates. The criterion of voluntarism was paramount here and the participants were all informed in advance of the framework and the conditions for conducting the research. In the following study the ten experiences and the ten beginners were selected according to their professional seniority (i.e., 10 years and more were considered experienced and less than 5 years were considered as beginners). According the ten trainee students were chooses according their availability in the school. To concretize this study, we used two investigative techniques: in the first place we proceeded by video recording of gymnastics sessions at the rate of two sessions per teacher. These sessions had an average duration of 55 minutes. Teachers' interventions were filmed in situ, using three digital cameras, one of which was placed on the teacher's head, but it allowed him total freedom of movement in order to collect all the verbal communications and all the angles aimed at by the teacher. A second camera is manipulated by the researcher who follows all movements all the movements of the teacher at a respectable distance ensuring, broad shots capturing all the interventions of the teacher with his students. A third camera mounted on tripods, in a corner of the gym, provides very wide shots, allowing for permanent viewing of the teacher and all students. Secondly, two interviews with each participant were recorded: following the first session, a semi-directive interview is conducted and recorded, using a tape recorder, with each teacher filmed, in order to collect, at first, the conceptions that make teachers of the distance they observe in relation to their students in the course of their teaching practices. Self-confrontational interviews, which serve to document the pre-reflexive experience of the actor (Theureau, 1992), were made immediately after the second practical session. A laptop and a video projector allowed the viewing and projection of the videotape of the recorded lesson. A tape recorder allowed audio recording of post-lesson interviews. The playback of the video is interrupted by the pause, advance, return at any time at the request of the teacher or on the part of the researcher. The teacher is confronted, at every moment, with his actions of which he is invited, by semi-open questions and based on the 
video, to explain what he did, thought, took into account to act, perceived, felt, (Vermersch, 1994), without asking for justifications. For data processing we started with transcripts of semi-directive interviews and self confrontation. Then we transcribed the practical sessions as a two-part table, for the teacher's and students' component 1 , and for the teacher's verbatim part 2. Finally, we used the MB-Ruler software to measure the interpersonal distance according to the different placements of the teacher compared to the student during four moments of intervention defining the different placements of the teacher.

In a second step, we submitted the verbatim recordings as well as the responses of the two interviews to the content analysis technique in the form of the grids containing the declarations and the realizations. In the last step in the following study, we have used the SPSS software version 23 to analyze all data to collect all our results we applied the global and analytical chi-squared test and we also used the percentage calculations for well-defined data, as well as that, calculates the average for interpersonal distances.

\section{Results Analysis}

\subsection{Proxemic Categorizations in PSE Sessions by Professional Seniority}

We submitted the results obtained from semi-structured interviews, and the analysis of the teaching practice concerning the teacher's placements with respect to his students according to his professional seniority, at the Chi-square test. Here is the result:

According to Table 1 we note that significant differences are marked for teachers' declarations of PSE and those at the expense of professional seniority. On the other hand we do not affirm significant differences for the exploitation of the different categorizations proxemics in class and those to the detriment of the professional seniority.

Testimonials according to the conceptions: to answer the questions concerning the conceptions that the participants make of our study of the proxemical categorizations, observed at the practical sessions, a trainee student answered " $I$ think that the teacher must be all the time close to the student especially in EPS plus the teacher is close to his student and the session succeeds". A beginner teacher replied, "We are EP teachers, we will have more contact than other teachers. For me sometimes close times away, it depends on the situation." An experienced teacher answered "The pupil is there, he works, I do not intervene, I

Table 1. Distribution of teachers' declarations and practical accomplishments by seniority in their proxic categorizations during PSE sessions.

\begin{tabular}{cccc}
\hline & Teacher profile & Value & P Value \\
\hline \multirow{2}{*}{ Pearson Chi-square } & Declarations & 40,480 & 0.002 \\
& achievements & 86,800 & 0.396 \\
Number of valid observations & & 30 & \\
\hline
\end{tabular}


am often at a distance, I do it on purpose to see how he behaves, to be very close is to watch him all the time, I approach when the student needs my help."

Testimonials according to the practice: A trainee student answered "Good everyone in his workshop and I circulate to check, good here I must pay more attention to the accidents especially for the girls and then here I allow myself to go away to observe". A beginner teacher answered "There you see, I move from one workshop to another, I pay attention by moving and I put myself closer to the workshop where there is more risk so for my case this workshop, then I retire." An experienced teacher "The work by workshop is not easy, I pay attention to my placement, I stand aside to see everyone, then I approach this workshop to the parade, and I give instructions at once it's about girls, it's a bit risky there."

According to the statements, we notice a deterioration of the teacher/student distance influenced by the seniority of the profession. This distance increases with the seniority of the teacher. The experienced teacher chooses to be often distant in order to allow the autonomy of the pupils and he approaches only to answer a need to feel for the pupil. Whereas for the novice teacher it is the alternation between near and far, close to correct to help and to parry and far to observe the execution of the pupil. On the other hand, the trainee student prefers to stick to the students to secure them, especially during gym classes.

On the other hand practically, teachers as well as trainee students develop similar strategies for using proxemic categorisations with respect to their placement in relation to their students. The teachers circulate between the workshops for the correction but they remain vigilant for the safety of the pupils and especially the girls and they go away for the observation. Professional seniority modulates the conceptions that PS teachers make of the proxemic categorizations observed in the course of teaching practice, but it does not modulate the practical use of these categorizations.

\subsection{Proxemic Categorizations during PSE Sessions by Gender of PSE Teacher}

We submitted the results of the semi-structured interviews, and the analysis of the teaching practice about the teacher's placement in relation to his students according to his gender, to the Chi-square test. The result is shown on Table 2.

According to Table 2, we note that significant differences are marked for teachers' declarations of PSE and those to the detriment of gender. On the other hand we do not affirm significant differences for the exploitation of the different categorizations proxemics in class to the detriment of the kind.

Table 2. Distribution of teachers' statements and practical achievements by gender about their proxemic categorizations during PSE sessions.

\begin{tabular}{cccc}
\hline & Teacher profile & Value & P Value \\
\hline \multirow{2}{*}{ Pearson Chi-square } & Declarations & 33,138 & 0.001 \\
& Achievements & 59,933 & 0.335 \\
Number of valid observations & & 30 & \\
\hline
\end{tabular}


Testimonials according to the conceptions: As an example, in answering the question about teachers' conceptions of their placements in relation to their students, one man replied, "We must not forget that we work with boys and girls in an Arab-Muslim country and we must respect that too. Personally I approach all the pupils without exception, I correct and I touch the boys, for the girls I correct orally, but I never touch a gir". A woman answered for the same question "I call them my children so I have to get closer to them to encourage them to succeed and above all, to ensure their safety".

Testimonials by Practice: As an example to answer the question during the self-confrontation interview about their placement at the time of viewing the video tape of the practice session a male teacher commented "Be careful to placement when working by workshop, I stand aside to see how it goes, Well look there, I approach to parry myself girls for security." One female teacher commented, "I pulled out to see there and then I got closer so that this student feels safe, I helped him and he managed."

According to the statements, for the male teachers the interpersonal distance varies according to the situation but they prefer to be distant especially with respect to the girls evoking that they must respect their belonging to an Arab-Muslim culture. Here we notice the effect of a male stereotype. Male teachers think under the influence of their masculine identity. Women are more affective and reassuring. They prefer to get closer to the students. Female teachers too are influenced by their identity as women. In practice, teachers, both men and women, adopt the same strategy concerning the proxemic categorizations observed with their pupils. They approach for the individual correction of the student and they move away to observe the whole class.

However, teachers, men and women, remain vigilant for the safety of students and especially girls. Gender shapes teachers' conceptions of proxemic categorizations observed in teaching practice, but it does not modulate the practical use of these categorizations.

From the results of the global chi-squared test we note that gender and professional seniority modulate PSE teachers' conceptions of proxemic categorizations observed during teaching practice, but they do not modulate the practical use of these categorizations.

\section{Detailed Analysis of Interpersonal Distance Management during Teaching Practice}

\subsection{The Analytical Chi-Squared Test}

We have deepened our research at the level of details of interpersonal distance management exploited by the teacher in class according to the seniority and gender. We analyzed the items used by all teachers, including student trainees, to compare with their students. We submitted our results to the chi-squared analytic test. Table 3 summarizes the results obtained.

According to Table 3, there are no significant differences between proxemic 
Table 3. Proxemic categorization of the PSE teacher.

\begin{tabular}{ccc}
\hline Teacher profile & Seniority & Gender \\
\hline Proxemic categorization during & & P value \\
Presentation of the task & 0.232 & 0.210 \\
Demonstration of the teacher & 0.234 & 0.269 \\
Correction of gesture technique & 0.396 & 0.271 \\
Observation & 0.379 & 0.315 \\
\hline
\end{tabular}

categorizations observed by teachers during their teaching practice at the expense of seniority and gender. So, all teachers, including student trainees, vary their placements in the classroom to meet the needs of the student.

\subsection{Calculate Percentages}

We submitted the correction using the physical contact used by all teachers, including trainee students, to place themselves in relation to the student during the teaching practice to the percentage. The results are shown schematically by the following histograms:

According to Figure 1, we note that the percentages of the corrections by the physical contact do not differ among the experienced teachers and the beginning teachers as well as with the trainee students thus the professional experience does not affect the correction by the touch of the pupils during PSE sessions.

According to Figure 2, we find that experienced teachers correct boys and girls equally by touch. While novice teachers correct by touch more girls than boys. On the other hand, trainee students correct more by touching boys than girls. We therefore note that work experience affects touch according to the sex of the student.

According to Figure 3, we notice that women approach and correct and help students by physical contact more than men. We therefore deduce that the teacher's gender affects the frequency of touch operation during the PS lesson.

According to Figure 4, we notice that male teachers correct by touch more boys than girls. Conversely, women correct more girls by touch than boys. This can be explained by the fact that women remain more affectionate and want to get girls to boys' level. On the other hand the male teachers accept the challenge and they want to progress with the boys according to a work of force.

According to Figure 5, we notice that the girls are corrected and helped by the touch more than the boys that can be explained by the weakness and the laziness of the girls. They constantly need help.

The results according to the global and the analytical chi-squared tests show that there are no significant differences between the management of proxemic categorizations of teachers during the practical sessions and that according to the gender and the seniority of the teacher. On the other hand, the results according to the percentages of the teachers' close or intimate distance parameters during teaching practice reveal that gender and seniority affect the use of touch 
Percentage of touch by seniority of PSE teacher

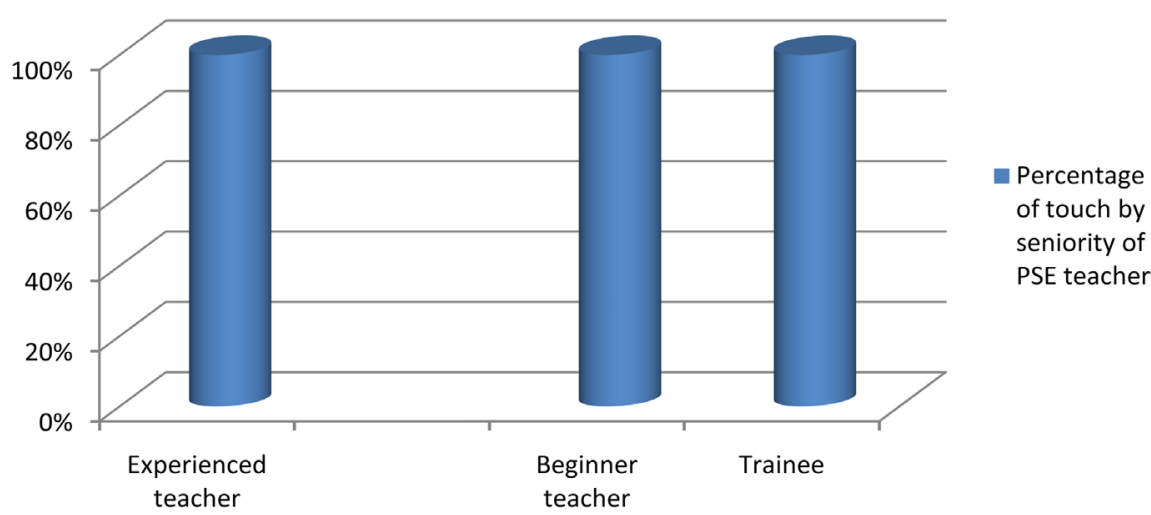

Figure 1. Percentage of touch by seniority of PSE teacher.

Percentage of touch by gender of PSE teacher

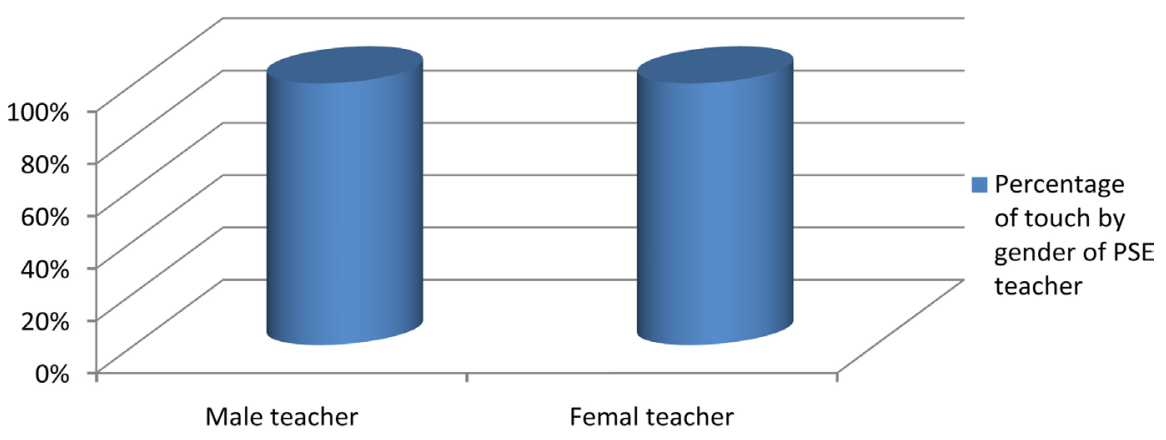

Figure 2. Percentage of touch by gender of PSE teacher.

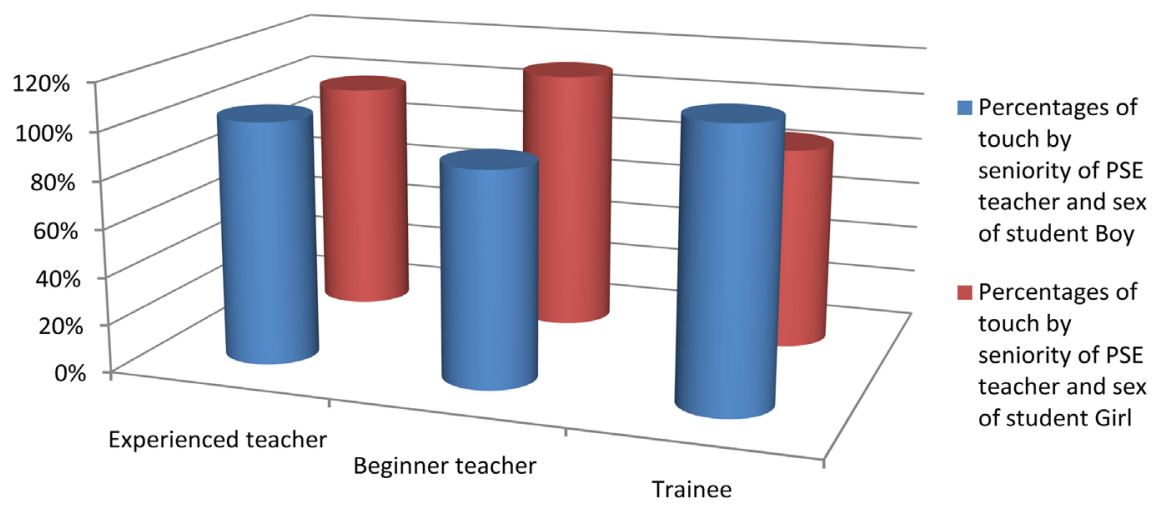

Figure 3. Percentages of touch by seniority of PSE teacher and sex of student.

during PS sessions.

\section{Didactic Distance during PSE Sessions}

\subsection{Didactic Distance at the Expense of Seniority and the Kind of PSE Teacher}

Using the MB-Ruler software we were able to determine the different proxemic categorizations of the PSE teacher during the different crucial moments of 


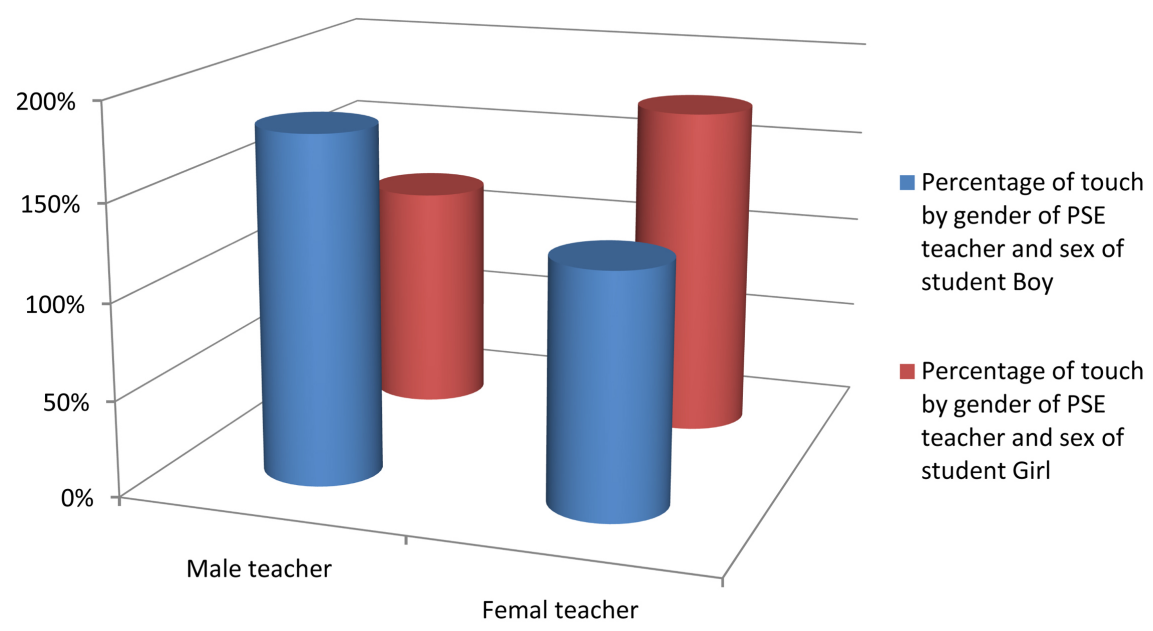

Figure 4. Percentage of touch by gender of PSE teacher and sex of student.

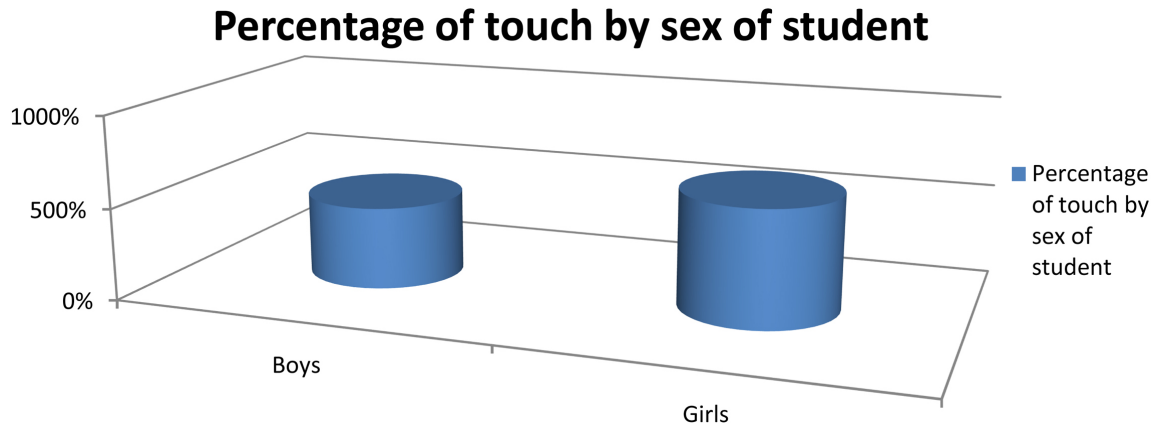

Figure 5. Percentage of touch by sex of student.

teaching practice. The averages of the interpersonal distances observed during the practical sessions are distributed in histograms and this to the detriment of the seniority and the kind of the teacher of PSE.

According to Figure 6 and Figure 7, we find that teachers and student trainees use the same proxemic categorizations during practical sessions. We note that participants in our experiment place themselves at a great distance from their students when observing the workflow. This distance decreases during the explanation and the demonstration to allow the students to listen well and see the teacher. This distance decreases again during the correction until the possibility of correcting the pupil by the physical contact and the touch.

\subsection{Proxemic Categorizations Observed by the Teacher during Practical Sessions in PSE}

By analogy with the proxemic typology of Hall (1963) and Sensevy et al. (2005) and in order not to fix the distance to a measurement near we have detected the lower and upper bounds of the measurements to ensure a range of measurement during the different moments of placement of the teacher of PSE.

According to Table 4, we find that teachers and trainee students use the same proxemic categorizations during practical sessions. We notice that the participants 


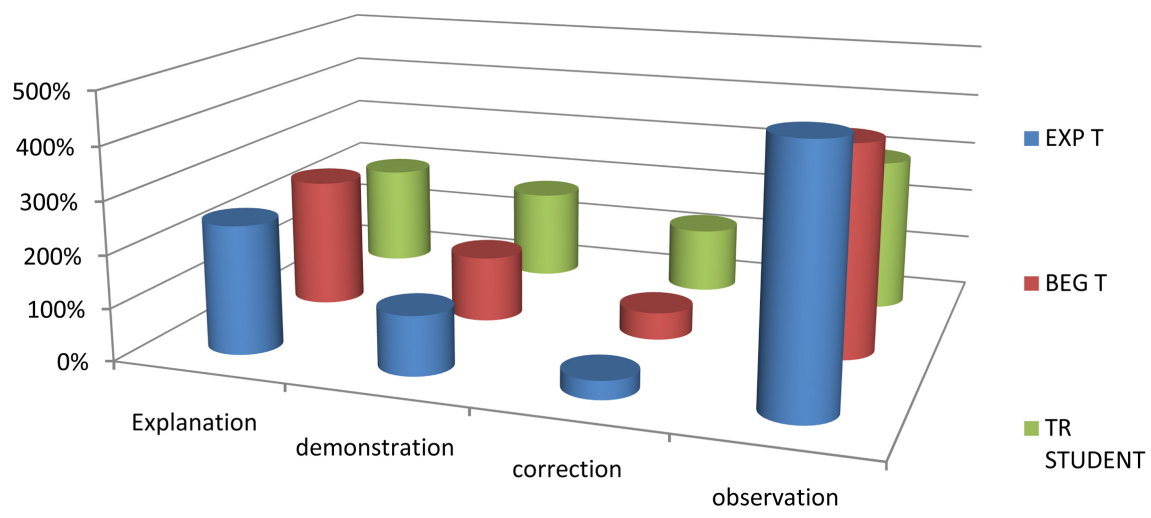

Figure 6. Didactic distance to the detriment of the seniority of the PSE teacher during practical sessions.

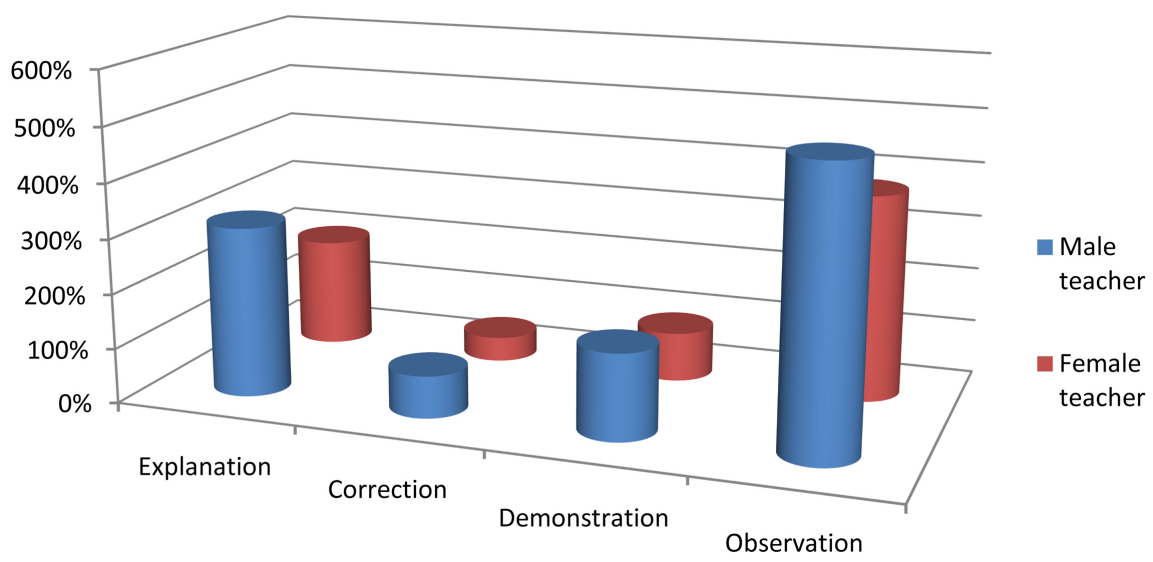

Figure 7. Didactic distance to the detriment of the gender of PSE teacher during practical sessions.

Table 4. Proxemic typology of the PSE teacher during gymnastics sessions.

\begin{tabular}{cccc}
\hline \multirow{2}{*}{ Configuration } & \multirow{2}{*}{ Utility } & \multicolumn{2}{c}{ Range of distance in cm } \\
\cline { 3 - 4 } & & Lower bollard & Upper bollard \\
\hline Public & Observation & 290 & 475 \\
Social & Explanation & 130 & 355 \\
Personal remote & Demonstration & 95 & 205 \\
Personal close or intimate & Correction & 17 & 192 \\
\hline
\end{tabular}

of our experiment are placed at a great distance from their students during the observation of the workflow. This distance decreases during the explanation and the demonstration to allow the students to listen well and see the teacher. This distance decreases again during the correction until the possibility of correcting the pupil by the physical contact and the touch.

\section{Discussion}

We are aware that our results obtained from the empirical survey are not generalizable. Indeed, we worked on a sample of convenience, composed of 20 
teachers of EPS and 10 students trainees practicing in governorates of Tunis I and II, Manouba, Ariana and Ben Arous. This sample does not represent all the teachers practicing in the 180 high schools of Tunisia. This is why we invite our colleagues from other Higher Institutes of Sport and Physical Education who wish to repeat the same empirical investigation to extend the results to all teachers. And we are willing to provide them with the experimental protocol used.

In this section we will compare our results with publications on the same theme. The discussion points will focus on the proxemic categorizations used by the teacher during his intervention. The main results of this study tend to show that teachers put forward different conceptions of their teaching practices, except that practically they present stable forms and common strategies of classroom placements.

These results coincide with the earlier work of several authors. Some authors (Nault \& Fijalkow, 1999) consider it difficult to move from "idealistic representation" to everyday practice. For Boizumault \& Cogérino (2012), contradictions appear in the comments about the initial beliefs when the teachers see themselves in the action confronted with the video of practical session.

\section{Seniority of the Teacher/Proxemic Categorization}

The teachers participating in this study, including trainee students without taking into account their seniority, alternate their placements to the daily teaching practice. They approach the students for correction but especially to ensure their safety and they move away to observe the whole class. Some authors (Rix \& Biache, 2002) demonstrate that space is inseparable from the interaction of the teacher with his students, he structures this interaction.

The French author (Couchot-Schiex, 2007) asserts that teachers are physically closer to girls, but against boys they interact at a distance. Vinson (2013), confirms that the majority of nonverbal interactions are in favor of girls to the detriment of boys. These results are consistent with our results, for our case the teachers approach to correct all the pupils on the other hand they correct by the touch more the girls than the boys.

Boizumault \& Cogérino (2010) consider touches in PSE sessions as a teaching tool made available to the teacher using it spontaneously when it is useful in learning situations. For our study, the teachers participating in our experiment, as well as the trainee students, correct the students by touch. The latter is used as a teaching medium to reinforce student learning.

This author (Vinson, 2013), At the end of his thesis argues that teachers of PSE, use the same categorization proxemics (social distance, personal and intimate), distances, personal and intimate, are the most used then appears the social distance and finally the public distance remains the least frequented. The author notes that teachers promote teacher proximity, taught since the three closest distances are the most used. The only difference is in the level of use of the intimate distance that dominates for the female teacher, while the man 
scores a certain balance in the use of different distances (alternates distances: far, medium and near). On the other hand, as much for the male teacher as for the female teacher, the intimate distance is mainly observed for the girls. For our study PSE teachers, use the same proxemic categorization. Intimate or near distance and public distance are the most used with dominance of intimate distance. For our study also women use more correction by physical contact than men and girls are more corrected by touch than boys.

The touches in EPS (Boizumault \& Cogérino, 2010), motivate the student and encourage his participation and his investment in the lesson. These authors assert that both the male teacher and the female teacher exploit the touch in a similar way, except that men develop more limits in their statements than women. At the level of beliefs, teachers are allowed to reach students while teachers must be vigilant, especially for contacts that may be poorly perceived.

For our study, teachers say that they are vigilant when it comes to girls as they belong to an Arab-Muslim culture, whereas women are free to touch boys as well as girls. For these researchers (Boizumault \& Cogérino, 2010), practically, it is the personality and previous experiences (socio-cultural factor) of the teacher that are at the origin of the behavioral differences between the two sexes. Some people are distant in nature, avoid physical contact, proximity, others, on the contrary, are tactile. For these authors and by analogy, the teacher is a person who is not devoid of affects and his personality impacts the way he teaches. For our study, we found that men correct boys more by touch than girls, while female teachers touch girls more than boys. We note that feminine and masculine identities affect the professional identity of the PSE teacher for correction by the touch of his students.

\section{Conclusion}

Statements collected through the first semi-directive interview show different conceptions of PSE teachers, including trainee students, about proxemic categorizations observed in the classroom. These remain dependent on the seniority and gender of the PSE teacher. On the other hand, the data collected through the analysis of the practical sessions and the self confrontation interview show that the teachers observe the same proxemic categorisations with their pupils. They approach for the individual correction of the student and move away to observe the whole class. However, teachers remain vigilant for the safety of students and especially girls.

Thus we notice that the conceptions of the teacher are not always consistent with his teaching practice. As a result, the gap between conceptions and teaching practices depends on professional seniority and the type of PSE teacher. The female teacher thinks more with her feminine identity and acts, as well, with her feminine identity as her professional identity. She is affectionate and reassuring in her placements in relation to her students. On the other hand, the masculine stereotype modulates the thoughts of the male teacher. The actor thinks that 
girls should not be approached out of respect for their Arab-Muslim culture. These interferences of identities facilitate and favor the teaching practice of women whereas the masculine stereotype widens the gap between the teaching practices of the man and his conceptions.

The intervention strategies during the practical sessions of the gymnastics activity are marked by regularity and typicality. PSE teachers use the same proxemical categorizations during teaching practices. They use a proximity for an individualized intervention and a great distance to supervise the class group. However, being vigilant in gymnastics to ensure the safety of students and especially that of girls remains an obligation.

\section{References}

Boizumault, M. B., \& Cogérino, G. (2010). Les touchers en EPS: Catégorisation, croyances des enseignants et perceptions des élèves. Paper presented at the l'Actualité de la recherche en éducation et en formation (AREF), Université de Genève.

Boizumault, M. B., \& Cogérino, G. (2012). La mise en scéne corporelle de l'enseignat d'EPS: Les communications non verbales aux service de l'efficacité de l'enseignant Staps, 98, 67-79.

Burel, N. (2014). L'ancrage des compétences émotionnelles dans le corps vivant: Etudes auprès d'enseignants d'Education Physique et Sportive. Recherches et éducations, 12, 89.

Couchot-Schiex, S. (2007). Observation des pratiques des enseignant (es) d'EPS au regard du genre. Recherche et Formation, 54, 151-164. https://doi.org/10.4000/rechercheformation.951

Forest, D. (2001). Distance élèves-maitre en activité didactique. Analyse de comportements proxémiques des professeurs en classe primaire. Mémoire de DEA en sciences de l'éducation, Université de Nantes. Université de Nantes.

Forest, D. (2006a). Analyse proxémique d'interactions didactiques. Carrefours de l'éducation, 1, 73-94.

Forest, D. (2006b). Analyse proxémique d'interactions didactiques. Université de Rennes 2.

Forest, D. (2008). Agencements didactiques: Pour une analyse fonctionnelle du comportement non-verbal du professeur. Revue Française de pédagogie, 165, 77-89. https://doi.org/10.4000/rfp.1108

Genevois, G. (1992). Etho-psychologie des communications et pédagogie. Revue Française de pédagogie: RFP, 100, 81-103. https://doi.org/10.3406/rfp.1992.1321

Hall, E. T. (1963). Asysteme for a Nota of Proxemic Behavior. American Anthropologist, 65, 1003-1026. https://doi.org/10.1525/aa.1963.65.5.02a00020

Hall, E. T. (1968). Proxemics. Chicago Journal the Wenner Gren Foundation for Anthropological Research, 9, 83-108.

Hall, E. T. (1971). La dimension cachée. Paris: Seuil.

Martinand, J. L. (1981). Pratiques sociales de référence et compétences techniques. A propos d'un projet d'initiation aux techniques de fabrication mécaniques en classe. In A. Giordan (Ed.), Diffusion et appropriation du savoir scientifique: enseignement et vulgarisation. Actes des troisièmes journées internationales sur l'Education Scientifique (pp. 149-154). Paris: Université Paris 7. 
Nault, T., \& Fijalkow, J. (1999). Introduction. la gestion de la classe: d'hier à demain. Revue des sciences de l'éducation, 25, 451-466. https://doi.org/10.7202/032009ar

Rix, G., \& Biache, M.-J. (2002). Étude de l'espace dans l'interaction entre une stagiaire d'éducation physique et sportive et ses élèves. Revue des sciences de l'éducation, 28 , 693-710. https://doi.org/10.7202/008339ar

Sensevy, G., Forest, D., \& Barbu, S. (2005). Analyse proxémique d'une leçon de mathématiques: Une étude exploratoire. Revue de sciences de l'éducation, 31, 659-686. https://doi.org/10.7202/013914ar

Theureau, J. (1992). Le cours d'action: Analyse sémiologique. Berne: Peter Lang.

Vermersch, P. (1994). L'entretien d'explicitation. Paris: ESF.

Vinson, M. (2013). Sous la dynamique non verbale des intéractions didactiques, le genre: Analyse de l'action conjointe du professeur et des élèves: Deux études de cas en EPS. Toulouse II: Université Toulouse le Mirail. 